\begin{tabular}{|c|c|c|c|c|c|c|}
\hline \multirow{2}{*}{ n } & $E J O P$ & 407 & \multirow{2}{*}{$\mathbf{B}$} & Dispatch: 8.3 .10 & Journal: EJOP & CE: Bindu \\
\hline & Journal Name & Manuscript No. & & Author Received: & No. of pages: 18 & PE: Naseern Taj/Bhuvana \\
\hline
\end{tabular}

DOI: $10.1111 /$ j.1468-0378.2010.00407.x

\title{
Action-oriented Perception
}

\author{
Bence Nanay
}

\begin{abstract}
When I throw a ball at you, do you see it as catch-able? Do we perceive objects as edible, climbable or Q-able in general? One could argue that it is just a manner of speaking to say so: we do not really see an object as edible, we only infer on the basis of its other properties that it is. I argue that whether or not an object is edible or climbable is indeed represented perceptually: we see objects as edible, and do not just believe that they are. My argument proceeds in two steps. First, I argue that in order to perform an action Q with respect to an object, we need to represent this object as Q-able and, second, I argue that we represent objects as having these properties perceptually.
\end{abstract}

I will assume that perceptual states represent objects as having various properties. ${ }^{1}$ They represent the perceived object as having a certain color, a certain shape and a certain spatial location, for example. The question I would like to examine here is whether they can represent objects as having a kind of property that is less obviously perceptual: the property of being edible, climbable or Q-able in general.

Most of the discussion about what properties are represented perceptually concerns sortal properties. When I am looking at the object in front of me do I perceive it as a table or do I perceive it as having a certain shape, size and color and I only infer that it is a table? In other words, besides the properties of having certain shape, size and color, is the property of being a table also represented in perception? I will not take sides in this debate, as my aim is to show that properties that could be thought of as even less obviously perceptual are represented in perception: the property of being edible, climbable or Q-able in general.

We sometimes say that we perceive objects as edible or climbable. In general, we say that we see objects as Q-able for us, where $Q$ is a certain goal-directed action. $^{2}$ The question is whether this is just a manner of speaking or we really represent these properties perceptually. I will argue that we do represent these properties perceptually: we do perceive objects as edible or climbable.

My argument proceeds in two steps. First, I argue that in order to perform an action $\mathrm{Q}$ with respect to an object, we need to represent this object as Q-able and, second, I argue that we represent objects as having these properties perceptually.

Before we begin, however, we need to examine what ' $Q$-ability' means.

\section{What is Q-ability?}

First of all, Q-ability is a relational property. The Q-ability of an object is a property that is partly determined by the features of the object and partly by the

European Journal of Philosophy un:u ISSN 0966-8373 pp. 1-17 (C) 2010 Blackwell Publishing Ltd., 9600 Garsington Road, Oxford OX4 2DQ, UK and 350 Main Street, Malden, MA 02148, USA. 
features of the agent for whom this object is Q-able. In other words, Q-ability is always Q-ability for a certain specific agent. The same tree can be climbable for me but not for a dog.

In the light of this, we can give a simple, but not very informative definition of the property 'Q-able': an object is Q-able for a certain agent if and only if this agent can $Q$ it. The right hand side of this definition, however, can mean a number of different things.

Without intending to give a precise analysis of sentences containing 'can', I will use a minimal definition for $Q$-ability. Object $x$ is $Q$-able for agent $A$ at time $t$ in circumstances $C$ if and only if it is not impossible for $A$ to $Q x$ at $t$ in $C$.

What does it mean to say that it is not impossible to perform $Q$ ? What sense of possibility is in use here? Appealing to nomological possibility would give us too weak a notion of Q-ability, since it is nomologically possible that I successfully climb a vertical wall made of polished marble without any special climbing equipment: it does not violate any physical laws to do so. Nevertheless, we perhaps do not want to call such a wall climbable for me.

There are many ways we could use for coming up with a less liberal notion of possibility in the definition of Q-ability. We could appeal to what Peacocke calls 'closeness possibility': the 'kind of possibility [...] under which something's being not possible means that in a certain way one can rely on its not obtaining (Peacocke 1999: 310). Or we could use a similar notion of possibility that Sainsbury calls 'easy possibility' (Sainsbury 1997, esp. p. 913). Or we could use a notion of possibility according to which it is possible for an agent to climb a wall if and only if the agent will successfully climb it in (sufficiently many of) those nomologically possible worlds where the agent's abilities and opportunities are the same as in the actual world. For the sake of generality, I will use a definition of Q-ability that is consistent with all of these ways of cashing out what is meant by possibility: an object $x$ is $Q$-able for agent $A$ at time $t$ in circumstances $C$ if and only if there is a sufficiently high number of relatively close possible worlds where A's attempt to $Q x$ at $t$ in $C$ succeeds. ${ }^{3}$

This definition does not aim to capture our everyday notion of 'edible' or 'climbable' as exactly as possible. The everyday notion of 'edible' or 'climbable' is often (perhaps even usually) understood as edible for agents in general and not as edible for a certain specific agent. My notion of Q-ability was supposed to capture the relational property of Q-ability for a specific agent. Whether or not my analysis is a correct everyday language analysis of the notion of 'Q-ability', what I am interested in is the property 'Q-able' (as I defined it) and not our everyday notion. I will argue that we represent objects as having this property.

The property of being Q-able will remind some of Gibsonian affordances (Gibson 1966, 1979). It is important to make it explicit that the claim I argue for in this paper is very different from the main claim of the Gibsonian theory of perception. The first important difference is that while Gibson argued that we perceive affordances (whatever they may be, see Fodor and Pylyshyn 1981), rather than objects, my claim is much more modest. I assume that what we perceive are indeed objects and I will argue that we (sometimes, not always)

(C) 2010 Blackwell Publishing Ltd. 
perceive objects as being Q-able. Further, the property of being Q-able is not the same as the property of affording action $\mathrm{Q}$.

The property of affording action $Q$, at least the way Gibson uses the concept, is a not a property of what we can do with an object, but what we should do with it. ${ }^{4}$ My claim is very different from (and, arguably, much weaker than) Gibson's: I do not aim to argue that we perceive objects as having properties of what we ought to do with them (although this claim has had a bit of revival recently, see Kelly forthcoming and Matthen forthcoming). ${ }^{5}$ My claim is that we perceive objects as having properties of what we can do with them.

Before I examine the question whether and how we represent objects as Qable, a word needs to be said about the scope of my claim: it needs to be clarified what kind of action $Q$ can be. We have already seen that $Q$ is taken to be a goaldirected action. But it is not even true of every goal-directed action $Q$ that we perceive objects as Q-able. It is not true of many mental actions and, as we shall see in Section 4, it is not true of highly complex actions like winning a war. I will say more about just what set of actions it is true that we perceive objects as Q-able in Section $4 .{ }^{6}$ But it is important to note here that the claim I defend in this paper is that there are some actions, $\mathrm{Q}$, such that we (sometimes) perceive objects as Qable. I do not claim that this is true of all actions. ${ }^{7}$

My strategy in the rest of the paper is the following. In the next section I aim to show that we represent objects as Q-able each time we are performing action $\mathrm{Q}$. Whether we do so perceptually is a question I postpone until the fourth section.

\section{The First Step of the Argument: We Represent Objects as Q-able}

There are lots of properties. Some of them we represent objects as having, but most of them we do not usually represent or we may even be incapable of doing so. We do not usually represent objects as having the property of being on a planet that also has lots of gothic cathedrals on it, for example. How about the property of Q-ability? Do we represent objects as Q-able for us? The short answer is that we must (at least sometimes) represent objects as Q-able for us, otherwise we could not $Q$ these objects.

Thus, the claim I will argue for in this section is that Q-ing an object implies representing it as Q-able. Two important clarifications are in order. First, the representation of the object as Q-able does not have to be a belief that the object is Q-able. Nor does this representation need to be conscious (I will return to this point in the last section). All I claim is that Q-ing $x$ implies representing (not necessarily consciously) $x$ as Q-able. Second, for simplicity, when I say Q-ing or performing an action $Q$ in this section, this is not meant to imply that the performance of this action is successful. In our ordinary language saying that I perform an action often seems to imply that I do so successfully. But in order to perform an action successfully, more conditions need to be met. What I mean by performing an action $Q$ in this section is just initiating an action $Q$. Thus, when I

(C) 2010 Blackwell Publishing Ltd. 
am looking for a necessary condition for performing an action, what I am really looking for is a necessary condition for initiating this action. ${ }^{8}$

What makes actions more than just bodily movements? Whatever it is that makes the difference, it must be a mental state that triggers, or maybe accompanies, the bodily movements. If bodily movements are triggered (or accompanied) by mental states of a certain kind, they qualify as actions. If they are not, they are mere bodily movements.

The big question is of course what mental states are the ones that trigger (or accompany) actions (see Brand 1984 for a detailed analysis of various ways of answering this question). The most popular candidate is intention. A standard way of explaining the difference between actions and mere bodily movements is that while the former are triggered by intentions, the latter are not. If I form an intention to raise my arm and this intention triggers the bodily movement of my arm going up, this makes it a genuine action. If the same bodily movement is triggered by a neuro-scientist fiddling with my brain and not by my intention, then we talk about a mere bodily movement.

This way of thinking about the difference between actions and bodily movements is both controversial and not sufficiently clear. What are intentions? John Searle famously differentiated prior intentions from intentions in action (Searle 1983: 83-98, see esp. p. 93). The former is not necessary for actions, whereas the latter is. In the case of some actions, the bodily movement is not caused by any prior intention, but it is caused by an intention-in-action. When I suddenly stand up from my desk and start pacing around my office, I have not formed a prior intention to do so. Nevertheless it is a genuine action as my bodily movement is caused by my intention-in-action (and not by my prior intention).

As I want to make a very general claim about perception, I want to be as neutral with regards to various theories of action as possible. There are some potential problems with Searle's concept of intention in action (see O'Shaughnessy 1991), but the general point I want to make does not presuppose Searle's theoretical framework. All I assume is that there is a (not necessarily belief-like, but representational) mental state that is a necessary condition for performing an action. Possible candidates for such a mental state, besides Searle's intention in action, include Kent Bach's 'executive representation' (Bach 1978), John Perry's 'belief-how' (Israel et al. 1993), dynamic action schemas (Jeannerod 1997) and the simple concept of trying (Mele 1992: 58ff; Mele 1995: 40; Mele 2003: 179; Adams and Mele 1992: 326; see also Armstrong 1980). ${ }^{9}$

I will use Bach's concept of executive representation as my starting point, but the same argument could be rephrased in terms of any theory that talks about mental antecedents of actions that make them actions (as opposed to mere bodily movements). Here is what Bach says about executive representations:

In the course of doing something, one does not observe one's bodily movements as if they were occurring independently of that awareness, as would be the case if, for example, someone else were moving one's arms. When you are moving them yourself, at each moment you are aware not

(c) 2010 Blackwell Publishing Ltd. 
only of where they are but also of where they are going, and not as if you were predicting where they would go. I claim that action, unlike other behavior, essentially involves this experience of what is being done and of what is to be done next [...]. (Bach 1978: 365-66)

Bach calls the 'awareness of what is being done' receptive representation and the 'awareness of what is to be done' effective representation. He calls then generically executive representations (Bach 1978: 366). In this passage, Bach talks about the awareness or experience of where my arms are and where they are going, but he immediately, and rightly, observes that this is too strong: the way we represent where our arms are and where they are going does not need to be conscious (Bach 1978: 366). In fact, one of the important differences he points to between intentions and executive representations is that the latter does not have to be conscious (Bach 1978: 367).

Thus, we can say that executive representations are the (not necessarily conscious) representations of where my arms are and where they will be. And executive representations are the mental states that are necessary for actions: they make actions genuine actions and not mere bodily movements. So the question is what is really being represented by these executive representations.

Bach is very explicit about this: 'When you are moving [your arms] yourself, at each moment you [represent] not only [...] where they are but also [...] where they are going, and not as if you were predicting where they would go' (Bach 1978: 366). What is important for our purposes is the second conjunct: when moving my arm, I need to represent where it will be at the next moment, that is, where I will put it. But what does this mean?

Suppose that I am reaching out for my coffee cup. If this action is a genuine action and not just a mere bodily movement, I need to represent where it will be at the next moment when it reaches the coffee cup. This means that I need to represent my hand at a certain spatial location (where it would reach the cup) at the next moment. But, as Bach emphasizes, I need to represent my hands 'not as if [I was] predicting where they would go' (Bach 1978: 366). In other words, I need to represent them at a certain spatial location (where it would reach the cup) in such a way that this state of affairs is a result of what I will do with them (as opposed to where I'll happen to find them). My claim is that I could not represent my hands reaching the cup in such a way that this is a result of what I will do with them, unless I represent the cup as reachable. If I did not represent the cup as reachable, as something I can reach, I could not represent my hands reaching the cup in such a way that this is a result of what I will do with them. I could, of course, represent them 'as if I was predicting where they would go', but it is difficult to see how I could do so in such a way that this is a result of what I will do with them.

Moving away from the specifics of Bach's account, the general point is that the performance of an action presupposes some kind of representation of the goal of this action: of the state of affairs the action aims to bring about. I understand 'goal' to be the immediate outcome of the action performed (see Brand 1984: 212-215

(C) 2010 Blackwell Publishing Ltd. 
on the ambiguity of this term). Different philosophers of action describe this representation of the goal differently (as 'goal representation' (Hommel et al. 2001), 'goal state representation' (Millikan 2004, chapter 16), 'anticipatory image' (James 1890, vol 2: 501), 'response image' (Greenwald 1970; Goldman 1970; see also Brand 1984: 174ff), 'motor response schema' (Schmidt 1975), 'representation of goals for actions' (Jeannerod 1994, Section 5; Jeannerod 1997; Jacob and Jeannerod 2003: 202-4), to mention just a few. But they all agree that the performance of an action presupposes some kind of representation of the goal of this action. In the case of the example I used above, I need to represent my hand touching the cup.

Importantly, it is not enough to represent the goal of the action as an outcome we predict or wish for or just dream about. We need to represent it as something that we are in the position to achieve. Again, different philosophers expressed this idea differently. Marc Jeannerod, for example, says that the goal is represented in a 'pragmatic mode of representation' (to be contrasted with the semantic one) (Jeannerod 1994, Section 5; Jeannerod 1997: 77; Jacob and Jeannerod 2003: 249-52; Pacherie 2000: 409-14). Myles Brand says that 'the subject must see the goal as his goal' (Brand 1984: 213). Again, the idea is clear: in order to perform an action, one needs to not only represent the goal of this action, but also have some idea about how this state of affairs is to be brought about. This second condition is especially explicit in John Perry's account. Perry argues that the representation of how the token action is to be performed, which he calls 'belief-how', is a necessary element of what he calls 'the motivating complex' (Perry 2001; Israel et al. 1993, Section 5). In other words, according to Perry, in order to perform an action, we need to have a representation of how this action is to be performed.

To sum up, in order for an agent to perform an action, she needs to represent its goal as well as the way in which she will bring about this goal (there is a lot of independent empirical evidence for this, see, e.g., Pelisson et al. 1986; Paulignan, Jeannerod et al. 1991; Jeannerod 1986, 1988, 1990; and Paulignan, MacKenzie et al. 1991). But one could not represent the way in which one will bring about a state of affairs without representing this state of affairs as attainable. To go back to the reaching for the coffee cup example, in order to perform this action, I need to represent its goal: my hand reaching the cup. I also need to represent the way in which I will bring about this state of affairs: the way in which I will move my hand there. But I could not represent the way in which I will move my hand there if I did not represent this state of affairs as attainable: if I did not represent the cup as being within my reach: as reachable. In short, performing the action of reaching for the cup implies representing it as reachable. The same argument applies for any other goal-directed action: each time we are Q-ing an object, we must represent it as Q-able.

Now one may wonder: aren't there some obvious counterexamples to this claim? Suppose that James Bond is trying to diffuse a bomb that has hundreds of wires and he has no idea whether he can defuse it. He is performing an action: the action of diffusing the bomb. But does he represent the bomb as diffusible?

(C) 2010 Blackwell Publishing Ltd. 
After all, he has no clear idea how to. The answer is that he does indeed represent the bomb as diffusible: he represents it as something that is not impossible to diffuse. He does not represent this task to be impossible, only very unlikely.

Here is another potential counterexample. I know that I cannot jump across the San Francisco Bay, but if someone threatens to kill me if I don't, I may try to do so. So I am performing an action: the action of jumping across the Bay, but, rightly, I represent this action to be impossible. Do we have a counterexample? No we don't. In this example, the action I am performing is not jumping across the Bay but trying to jump across the Bay, or jumping in such a way that this would count as an attempt at jumping across the Bay. So the action I am performing is that of trying to jump across the Bay. And trying to jump across the Bay is something I do not (and should not) represent to be impossible. ${ }^{10}$

I have talked about a necessary condition for the performance of an action: in order to perform action Q on $x$, I need to represent $x$ as Q-able. But it is important that this is a necessary condition for all performances, not just successful ones. If the performance of an action is successful, then, presumably, this representation needs to be correct: $x$ needs to be in fact $Q$-able. But the correctness of this representation does not guarantee the successful performance of the action: remember that x's being Q-able means only that it is not impossible for me to $Q$ it. It does not follow that my attempt of Q-ing it will in fact be successful.

It is very important to note that representing an object as being $Q$-able does not imply that the agent needs to master those concepts that appeared in the definition of Q-ability-nomologically possible worlds included. Representing a curve as a parabola does not imply that the agent masters the concepts that appear in the exact definition of a parabola (see, e.g., Rodriguez-Pereyra 2002: 94). It is enough if she can tell parabolas from non-parabolas (see Peacocke 2001). Similarly, the claim that each time we are Q-ing an object we must represent this object as Q-able does not imply that each time we are performing an action we must have some extremely complicated representation or that we must master some complicated concepts. This point will become important when we examine whether animals represent objects as Q-able in the last section.

\section{Perceptual and Non-perceptual Accounts of Representing Q-ability}

So far so good. We do represent objects as Q-able. But do we represent these properties perceptually? Do we see objects as edible or climbable?

A tempting way of analysing the representation of Q-ability would be to say that we do not really perceive properties of this kind. The property of being edible or climbable is not represented by my perceptual state, but by some nonperceptual mental state (say, a belief) that this perceptual state gives rise to.

We perceive an object as having certain 'observable' properties (color, size, shape), ${ }^{11}$ and on the basis of this perceptual state, we come to have a nonperceptual mental state that represents this object as edible. This transition from the perceptual state to the non-perceptual mental state may be an inference (Rock

(C) 2010 Blackwell Publishing Ltd. 
1983; Gregory 1966) or some noninferential process (Marr 1982; Fodor 1983). Whether it is an inference or not, the suggestion is that the perceptual representation of color, size and shape gives rise to the non-perceptual representation of Q-ability.

A good candidate for such non-perceptual mental state would be a belief. So in what follows, I will use 'belief that $\mathrm{x}$ is edible' as a shorthand for 'non-perceptual mental state that represents $x$ as edible'. But it is important that the nonperceptual account of representing Q-ability does not imply that this nonperceptual mental state is a belief. It may very well be any other non-perceptual mental state. I will talk about beliefs in the argument I present in the next section, but the concept of belief can be replaced with the concept of non-perceptual representation at every point of the argument: I do not make any assumption about beliefs that I could not make about any other non-perceptual representations.

On this non-perceptual view, saying that we see something as edible is only a manner of speaking or a non-literal use of the word 'seeing'. We do not see the object as edible, we see something else and (on the basis of, or, as a result of, being in this perceptual state) we believe that it is edible. There is nothing perceptual about the representation of edibility or climbability. We could call this way of explaining the representation of Q-ability the 'non-perceptual account'.

The alternative, perceptual, account states that the property of Q-ability is represented by perceptual states themselves. I will present an argument in favor of the perceptual account: I will argue that the property of Q-ability is perceptually represented.

Recent empirical literature on visual search seems to show that the perceptual account is more plausible (Humphreys and Riddoch 2001; Riddoch et al. 1998, esp. p. 678). In an experiment a patient, MP, who shows symptoms of unilateral neglect, ${ }^{12}$ was slow and sometimes even unable to find objects defined by salient visual property (such as their color). He was capable of and relatively efficient in finding objects defined by the action they can be used for. Thus, MP judged the object to have the property Q-able much before he was capable of judging that the object has certain visual properties, such as color. This suggests that the processing of the property of Q-ability does not depend on the processing of visual properties like color or shape. Whether or not it is possible to explain these results in a way that does not imply that we represent the property Q-able perceptually is an interesting question, but one I cannot address here. I take these empirical findings as merely suggestive and argue for this conclusion on independent, non-empirical, grounds.

\section{The Second Step of the Argument: We Perceive Objects as Q-able}

Suppose that the perceptual account is wrong: we do not see objects as Q-able. We see them as having certain shape and color and this perceptual state gives rise to another, non-perceptual mental state that represents the object as Q-able. We

(C) 2010 Blackwell Publishing Ltd. 
do not really see the object as edible or climbable, we see something else and we believe that it is edible or climbable. I will try to show that this view of the representation of Q-ability is implausible.

Let us see how this is supposed to work. My perceptual state represents the object as red and circular (or as a tomato) and this perceptual state gives rise to a belief or some other non-perceptual mental state, which represents the object as edible for me. How does this transition happen? Presumably, I do know that red and circular objects (or tomatoes) are edible, therefore, when I see an object as red and circular, I form a belief that it is edible. This piece of knowledge may or may not be explicit; this transition may or may not happen consciously. Whether this transition is a conscious inference will not matter for my argument.

So, I see a red round object, and, as a result (perhaps because I know that red round objects are edible), I represent the object, non-perceptually, as edible. One problem with this account is the following: in order for the perceptual state to give rise to a belief that the object is Q-able, we need a lot of contextual information about the situation: that the object is not behind glass, that it will not disappear when I touch it, and so on. If I see a red round object, this will give rise to a belief that it is edible only if I do not believe that it is behind glass and I do not believe that it will disappear when I touch it, and so on.

A possible worry is that we would need an extremely large number of beliefs about the object in order to represent it (non-perceptually) as Q-able: the belief that it will not disappear when we touch it, etc. I do not think that this worry is justified and it is important to emphasize that this is not the problem I have with the non-perceptual account. Not representing the object as something that will disappear once I touch it does not imply representing it as something that will not disappear once I touch it: not representing $\mathrm{x}$ as $\mathrm{F}$ does not imply representing $x$ as non-F. In other words, it is possible that we just take it for granted that objects we touch will not disappear with out explicitly representing it as something that will not disappear.

I want to raise a more serious problem with the non-perceptual account. We have seen that if we accept the non-perceptual account, then whether I represent the object as Q-able non-perceptually depends on a great number of contextual beliefs and/or background information. If I believed that the object will disappear when I touch it, I presumably will not represent (non-perceptually) it as Q-able for me now. It follows from the non-perceptual account that the representation of Q-ability is sensitive to a great number of our other mental states. So far nothing seems implausible. If we take the non-perceptual mental state that represents Q-ability to be a belief, then this is in fact what we should expect: one's belief, after all, are supposed to be sensitive to one's other beliefs. ${ }^{13}$

The problem is that this consequence of the non-perceptual account is false. The representation of Q-ability is surprisingly insensitive to other beliefs (or other non-perceptual mental states) of ours.

Take the following example: I am standing behind a strong piece of plexiglass knowing that there is plexiglass in front of me, when someone on the other side of the glass throws a beach ball at me and I reach out in an attempt to catch the

(C) 2010 Blackwell Publishing Ltd. 
ball. ${ }^{14}$ The claim is that I do represent the ball flying towards me as catch-able, but I firmly believe that I will not be able to catch it.

Let us go through this example more slowly. I make two claims: (a) I do represent the ball as catch-able and (b) I do know that the ball is not catch-able.

Claim (a) must be true, as the argument I presented in the second section showed that each time we are Q-ing an object, we must represent it as Q-able and in the scenario I described I am performing an action: the (unsuccessful) action of catching the ball. I make an attempt to catch the beach ball that I firmly believe never to be able to catch.

One may object that I cannot be described as performing an action at all. I just have a reflex-like bodily movement. There are (at least) three reasons why this bodily movement can be described as a genuine action, and not just a reflex. First, I can refrain from moving in this scenario, if I (really) want to. In the case of reflexes, the agent cannot help moving. When the doctor tests my knee jerk reflex, I cannot stop my body from moving. In the plexiglass example, I can. Second, in the case of reflexes the bodily movement tends to surprise us: it does not seem that the bodily movement was initiated by me. In the plexiglass example, on the other hand, the agent does not perceive her bodily movement as something initiated by someone else; we do not have the surprising feeling that our body is moved by someone else. Third, in the plexiglass example, my bodily movement varies as my representation varies: my bodily movement would be different if I represented the ball as flying towards me a bit lower or a bit higher. Similarly, my bodily movement would be different if I represented the ball as a tennis-ball or a basketball. Thus, the bodily response depends on the way the agent represents the world as being. In the case of reflexes, on the other hand, the bodily movement does not vary with the way the agent represents the world as being. No matter how I represent the doctor's hammer, my knee jerk reflex will be the same. Thus, in the plexiglass example, we do not have a mere reflex-like bodily movement: we are in fact performing an action: the (unsuccessful) action of catching the ball. Hence, we do represent the beach ball as catch-able. Claim (a) is true.

But (b) must also be true, since I do know that it is impossible for me to catch the ball-under any of the ways of conceiving of impossibility I have considered in the first section. I do know that there is a thick plexiglass between the ball and me and that there is no way (that is, no relatively close nomologically possible world where) my attempt to catch the ball would be successful.

Therefore, I do know that the ball is not catch-able. But I still represent it as such.

To sum up, even if I have all the evidence that the object is not Q-able, I cannot help representing it as Q-able. But as we have seen, a consequence of the nonperceptual account is that representing something as Q-able must be sensitive to our some of our other beliefs and other non-perceptual mental states, because I can represent something as Q-able only if I have a huge amount of contextual information and/or background beliefs. But we just pointed out that the representation of $\mathrm{Q}$-ability is not at all sensitive to our other beliefs. We have reached a contradiction.

(C) 2010 Blackwell Publishing Ltd. 
It is important to be clear about what the contradiction is. The plexiglass case shows that the belief that an object is Q-able is in conflict with our other beliefs about the object. What this finding contradicts is not the assumption that a belief of ours cannot be inconsistent with any of our other beliefs. Rational agents can have conflicting beliefs, though they cannot have too many of them all the time. ${ }^{15}$ The defender of the non-perceptual account could object that in the plexiglass example, we have conflicting beliefs for a moment only (for the moment when we believe that the ball is catch-able), but afterwards, this conflict is resolved. But this is not where the contradiction is supposed to be located.

What the plexiglass example contradicts is something the non-perceptual view relies on much more directly. The non-perceptual account presupposes that we could not have a non-perceptual representation of the object as Q-able unless we had some contextual information or assumption about the object: that it is not going to disappear if I touch it, etc. This is true of any non-perceptual representation, not only beliefs. Beliefs are famously sensitive to our other beliefs, but what matters here is something beliefs and any other non-perceptual representations have in common: that they have to be sensitive to contextual information or assumption about the object without which the object would not be represented as Q-able: that it is not going to disappear if I touch it, etc. We could not have the non-perceptual representation of the object as Q-able unless we had these other mental states. The plexiglass example directly contradicts this assumption. This example shows that this mental state is insensitive to the very mental states it is supposed to be based on.

The phenomenon that even if I have all the evidence that the object is not Q-able, I cannot help representing it as Q-able is consistent with the claim that Q-ability is perceptually represented. Perception is famously belief-independent: we cannot help seeing the Müller-Lyer illusion drawing as a picture of two uneven lines even if we know it perfectly well that the two lines are of equal length. Similarly, we cannot help seeing the object as Q-able even if we have all the evidence that it is not Q-able. ${ }^{16}$

If this argument is correct, then we do represent the property Q-able perceptually. We literally see objects as edible or climbable.

It is important to note that the argument I presented in this section uses a premise that is not satisfied in the case of all actions. This premise is that the representation of Q-ability must be the (inferential or non-inferential) result of a perceptual representation. There are some complex actions in the case of which we may represent something as Q-able without any perceptual basis-entirely on the basis of some beliefs of ours. Winning a war is a possible example. If I represent a war as winnable, I may do so (and I am likely to do so) not on the basis of a perceptual state of mine, but rather on the basis of some of my beliefs. In the case of actions of this kind, this argument will not work. This sounds right: the argument should not work in these cases either. It would sound odd to say that we perceive the 'winnability' of wars. ${ }^{17}$

These actions, however, are very complex ones and perhaps only available to adult human beings capable of linguistic reasoning. The kind of actions I am

(C) 2010 Blackwell Publishing Ltd. 
interested in here are much more basic - and the vast majority of our actions are like that. We could call these actions perceptually-guided actions: their performance must in some way depend on what we perceive: for performing these actions successfully, we need to (and do) take into consideration what we see. The vast majority of our actions are perceptually guided, but even those that are not perceptually guided (such as winning a war) could only be executed by performing perceptually guided actions. What I aimed to show in this section was that for each perceptually guided action $\mathrm{Q}$, it is true that we sometimes do see objects as Q-able.

\section{Conclusion: How Animals See the World}

Thus, some of our perceptual states represent objects as Q-able. I will call these perceptual states action-oriented perceptual states. Action-oriented perceptual states can of course misrepresent. They can represent an object as Q-able whereas in fact this object is not Q-able.

Action-oriented perceptual states by definition represent the perceived object as Q-able. This, however, is not the only set of properties these perceptual states represent the perceived object as having. Presumably, they also represent it as having other properties, such as having a certain color and being at a certain spatial location and perhaps even as having some other properties such as 'being a chair' or 'being made of mahogany'.

Action-oriented perceptual states may or may not be conscious. Sometimes we consciously represent the object we are looking at as edible, but we are sometimes performing action $Q$ with an object without consciously representing the perceived object as Q-able, for example when we are performing actions we are very much used to. ${ }^{18}$

Why should we be interested in these action-oriented perceptual states? One reason is that, if my argument in the second section is correct, we are in actionoriented perceptual states most of the time: each time we are performing an action. Even more importantly, animals and toddlers perform actions: they escape from predators and approach their prey. ${ }^{19}$ Hence, they must have actionoriented perceptual states, since, as we have seen, performing actions would be impossible unless they could represent objects as Q-able. Even if one denies that animals and small children have some more complex mental states (such as beliefs), if the argument I presented above is correct, they must have actionoriented perceptual states. Thus, action-oriented perceptual states seem to be basic both from a phylogenetic and from an ontogenetic point of view.

One could, of course, deny that animals and small children are capable of performing actions: the claim would be that they only have reflex-like bodily movement (see, for example, Davidson 1980 and Kennedy 1992). But the problem with this suggestion is that it goes against everything we know about the behavior of non-human animals. A general assumption of ethology is that animals perform goal-directed actions: actions that presuppose some kind of representation of a goal. ${ }^{20}$ We explain the bodily movement of a predator in such

(C) 2010 Blackwell Publishing Ltd. 
and such direction with reference to its representation of the prey as being in that direction. If it had not represented the prey there, it would not have moved that way. Reflex-like bodily movements, however, as we have seen in the fourth section, do not depend on the way the agent represents the world as being. Thus, we cannot explain why it moved in a certain way without making reference to its representations. Thus, if one does not want to deny that animals represent the world (or to claim that these representations are completely useless), then one needs to concede that animals are capable of performing actions. Thus, one also needs to concede that animals have action-oriented perceptual states. ${ }^{21}$

\author{
Bence Nanay \\ Department of Philosophy \\ Syracuse University \\ USA \\ nanay@syr.edu
}

\title{
NOTES
}

1 This is not an uncontroversial assumption. It has been argued that perceptual states do not represent anything (Travis 2004; Campbell 2002; and Nanay forthcoming for a summary). However, I will assume throughout the paper that perceptual states represent objects as having properties, but my argument can be rephrased in the non-representational, 'relational' framework of thinking about perception.

2 I will use the notion 'Q-able' as a schematic term for 'catch-able', 'climbable', 'edible', etc., throughout the paper. I will restrict the scope of actions I discuss to goal-directed ones. I discuss the rationale for this restriction at the very end of Section 1.

${ }^{3}$ What the expression 'sufficiently high number' amounts to in my definition would vary according to the context of the use of 'Q-able'. In some context we say that a slope is ski-able for me even if there is only a very slight chance that I can successfully ski it, whereas in some other context we call a slope Q-able only if there is a good chance that I can ski it. This context-sensitivity is very Lewisean in spirit (see Lewis 1986). Similar considerations apply in the case of the context-sensitivity of what is meant by 'relatively close possible worlds'.

${ }^{4}$ Gibson oscillates between these two interpretations of the concept of affordance, but his official definition is in terms of what we should do: he attributes full normativity to affordances (see especially Gibson 1979).

5 This stronger claim about the normativity of perception could be traced back to the Gestalt psychologists. As Kurt Koffka says, 'to primitive man each thing says what it is and what he ought to do with it [...] a fruit says "Eat me"; water says "Drink me"; thunder says "Fear me"" (Koffka 1935: 7).

${ }^{6}$ A particularly intriguing question is whether the action of seeing would qualify. If it does, we would need to conclude that we perceptually attribute the property of being visible to every object we see. Some seem to endorse such conclusion: Susanna Siegel argues that the 'perceptual relation of perspectival connectedness' is represented perceptually (Siegel 2006b) and this concept of 'perceptual relation of perspectival connectedness' may be closely related to the concept of visibility (thanks for Susanna

(C) 2010 Blackwell Publishing Ltd. 
Siegel for pointing this out to me-personal communication Summer 2008). I will not talk about the action of seeing and the property of being visible in what follows.

7 The grammatical form of talking about actions is very diverse. Sometimes we say that we perform $\mathrm{Q}$ on $\mathrm{x}$ or with $\mathrm{x}$, or with the help of $\mathrm{x}$. For simplicity, I will use the following terminology: an agent A Qs $x$ if an only if A performs an action $Q$ on/with/with the help of $x$.

8 As the successful performance of an action seems to imply that this action was initiated, this necessary condition will also be a necessary condition for performing this action successfully.

${ }^{9}$ I do not mean to suggest that these concepts pick out the same mental state, but I do believe that the argument I am about to give could be modified to fit any of these theoretical frameworks.

${ }^{10}$ See also Alfred Mele's related discussion about the distinction between trying and pretending to try (Mele 1992: 63).

${ }^{11}$ These observable properties may include relatively higher-order ones, such as that of 'being an apple'. See Siegel 2006a on the concept of 'observable properties'.

${ }^{12}$ Unilateral neglect is caused by brain lesions, primarily in the right parietal areas. Patients showing symptoms of unilateral neglect are unaware of the left hand side of their body and environment.

${ }^{13}$ It is important to stress that the non-perceptual representation of Q-ability depends on a great number of contextual beliefs and/or background information even if this nonperceptual representation is not a belief. The reason why the non-perceptual representation of Q-ability is sensitive to one's other mental states is not that it is a belief, but that if I believed that the object will disappear when I touch it, I presumably will not represent non-perceptually it as Q-able for me now.

${ }^{14}$ Charles Darwin uses a similar example: 'I put my face close to the thick glass-plate in front of a puff-adder in the Zoological Gardens, with the firm determination of not starting back if the snake struck at me; but, as soon as the blow was struck, my resolution went for nothing, and I jumped a yard or two backwards with astonishing rapidity' (Darwin 1899: 18.)

${ }^{15}$ See Harman 1984 for a classical analysis of the topic of contradicting beliefs.

16 There may be some interesting differences between the Müller-Lyer case and the Qability case. Seeing the Q-ability of an object may be easier to unlearn than seeing the Müller-Lyer illusion. These differences, however, do not affect the argument against the claim that Q-ability is represented non-perceptually. See Nanay 2009 for more on the Müller-Lyer illusion.

17 There may be a gray zone of actions for which it depends on the individual's abilities whether she sees objects as Q-able or represent them non-perceptually as such. An expert bridge player may be described as literally seeing a hand as 'two club-able': a hand that can be bid as two club, but a beginner may have to arrive at the conclusion that this hand is 'two club-able' by means of a non-perceptual inferential process (of tedious pointcounting).

18 I want to remain neutral about whether action-oriented perceptual states are part of the ventral or the dorsal stream of visual processing. Humans (and other mammals) have two visual subsystems that use different regions of our central nervous system, the socalled ventral and dorsal streams. To put it very simply, the ventral system is responsible for identification and recognition, whereas the function of the dorsal system is the visual control of our motor actions. In normal circumstances, these two systems co-function, but experiments show that if one of them is removed or malfunctioning, the other can still function relatively well (see Milner and Goodale 1995; Goodale and Milner 2004, for

(C) 2010 Blackwell Publishing Ltd. 
overview). The action-oriented character of action-oriented perceptual states may be taken to suggest that these states are part of the dorsal system. On the other hand, some (more importantly, Milner and Goodale) have argued that the visual processing in the dorsal stream is unconscious, whereas the ventral stream is the locus of conscious perception. This suggestion, however, has been repeatedly questioned (see for example Dehaene $e$ al., 1999; Jeannerod 1997; see also Jacob and Jeannerod 2003 for a summary). If it is true that only the ventral visual processing is conscious, then this would suggest that at least some of our action-oriented perceptual states are part of the ventral stream (because sometimes we do consciously represent the object we are looking at as Q-able). I do not want to take sides with either of these views.

19 Some philosophers would question this and say that animals do not perform actions - they only have bodily movements (see, for example, Davidson 1980).

${ }^{20}$ As Robin Dunbar summarizes, 'we need to determine not only what an animal does, but, more importantly, what it is trying to do' (Dunbar 1984: 231). Dunbar talks about organisms with very complex mental architecture (baboons), but the same argument has been made in connection with rattlesnakes (Theodoratus and Chiszar 2000) and even spiders (Jackson and Pollard 1996; Wilcox and Jackson 2002).

${ }^{21}$ I presented various earlier versions of this paper at the University of California, Berkeley, Rice University, Syracuse University, York University, Concordia University, University of Geneva and the University of British Columbia. I am grateful for all the feedback I received on these occasions. It would be impossible to acknowledge all who have commented on this paper, but I am particularly grateful for the comments of John MacFarlane, John Campbell, Fabrizio Cariani, Kevin Mulligan, Alva Noë, Liz Camp, Susanna Siegel and of the anonymous referees for the European Journal of Philosophy.

\section{REFERENCES}

Adams, F. and Mele, A. (1992), 'The Intention/Volition Debate', Canadian Journal of Philosophy, 22: 323-38.

Armstrong, D. M. (1980), 'Acting and Trying', in his The Nature of Mind and Other Essays. Ithaca, NY: Cornell University Press, 68-88.

Bach, K. (1978), 'A Representational Theory of Action', Philosophical Studies, 34: 361-79.

Brand, M. (1984), Intending and Acting. Cambridge, MA: MIT Press.

Campbell, J. (2002), Reference and Consciousness. Oxford: Oxford University Press.

Darwin, C. (1899), The Expression of Emotion in Man and Animals. New York: Appleton.

Davidson, D. (1980), Essays on Actions and Events. Oxford: Oxford University Press.

Dehaene, S., Naccache, L., Le Clec'H, G., Koechlin, E., Mueller, M., Dehaene-Lambertz, G., van de Moortele, P. F. and Le Bihan, D. (1999), 'Imaging Unconscious Priming', Nature, 395: 597-600.

Dunbar, R. (1984), Reproductive Decisions: An Economic Analysis of Gelada Baboon Social Strategies. Princeton: Princeton University Press.

Fodor, J. A. (1983), The Modularity of Mind. Cambridge, MA: MIT Press.

Fodor, J. A. and Pylyshyn, Z. (1981), 'How Direct is Visual Perception? Some Reflections on Gibson's 'Ecological Approach", Cognition, 9: 139-96.

Gibson, J. J. (1966), The Senses Considered as Perceptual Systems. Boston: Houghton Mifflin. — (1979), An Ecological Approach to Visual Perception. Boston: Houghton Mifflin.

Goldman, A. (1970), A Theory of Human Action. Englewood Cliffs, NJ: Prentice-Hall.

Goodale, M. A. and Milner, A. D. (2004), Sights Unseen. Oxford: Oxford University Press.

(C) 2010 Blackwell Publishing Ltd. 
Greenwald, A. (1970), 'Sensory Feedback Mechanisms in Performance Control: With Special Reference to the Ideo-Motor Mechanism', Psychological Review, 77: 73-99.

Gregory, R. (1966), Eye and Brain: The Psychology of Seeing. New York: McGraw-Hill Book Company.

Harman, G. (1984), 'Logic and Reasoning', Synthese, 60: 107-27.

Hommel, B., Müsseler, J., Aschersleben, G. and Prinz, W. (2001), 'The Theory of Event Coding: A Framework for Perception and Action Planning', Behavioral and Brain Sciences, 24: 849-931.

Humphreys, G. W. and Riddoch, M. J. (2001), 'Detection by Action: Neuropsychological Evidence for Action-Defined Templates in Search', Nature Neuroscience, 4: 84-8.

Israel, D., Perry, J. and Tutiya, S. (1993), 'Executions, Motivations and Accomplishments', Philosophical Review, 102: 515-540.

Jackson, R. and Pollard, S. (1996), 'Predatory Behavior of Jumping Spiders', Annual Review of Entomology, 41: 287-308.

Jacob, P. and Jeannerod, M. (2003), Ways of Seeing. The Scope and Limits of Visual Cognition. Oxford: Oxford University Press.

James, W. (1890), The Principles of Psychology. New York: Henry Holt and Co.

Jeannerod, M. (1986), 'The Formation of Finger Grip During Prehension: A Cortically Mediated Visuomotor Pattern', Behavioural Brain Research, 19: 99-116.

_ (1988), The Neural and Behavioral Organization of Goal-Directed Movements. New York: Oxford University Press.

- (1990), 'The Representation of the Goal of an Action and its Role in the Control of Goal-Directed Movements', in E. L. Schwartz (ed.) Computational Neuroscience. Cambridge, MA: MIT Press, 352-68.

_ (1994), 'The Representing Brain: Neural Correlates of Motor Intention and Imagery', Behavioral and Brain Sciences, 17: 187-245.

- (1997), The Cognitive Neuroscience of Action. Oxford: Blackwell.

Kelly, S, (forthcoming), 'The Normative Nature of Perceptual Experience', in B. Nanay (ed.) Perceiving the World. New York: Oxford University Press.

Kennedy, J. S. (1992), The New Anthropomorphism. Cambridge: Cambridge University Press. Koffka, K. (1935), Principles of Gestalt Psychology. New York: Harcourt Brace.

Lewis, D. (1986), On the Plurality of Worlds. Oxford: Blackwell.

Marr, David (1982), Vision. San Francisco: W. H. Freeman.

Matthen, M. (forthcoming), 'How Things Look (and What Things Look that Way)', in B. Nanay (ed.) Perceiving the World. New York: Oxford University Press.

Mele, A. (1992), Springs of Action. Oxford: Oxford University Press.

— (1995), Autonomous Agents. Oxford: Oxford University Press.

- (2003), Motivation and Agency. Oxford: Oxford University Press.

Millikan, R. (2004), Varieties of Meaning. Cambridge, MA: MIT Press.

Milner, A. D. and Goodale, M. A. (1995), The Visual Brain in Action. Oxford: Oxford University Press.

Nanay, B. (2009), 'Shape Constancy, Not Size Constancy: A (Partial) Explanation for the Müller-Lyer Illusion', in N. A. Taatgen and H. van Rijn (eds.), Proceedings of the $31^{\text {st }}$ Annual Conference of the Cognitive Science Society (CogSci 2009). Mahwah, NJ: Lawrence Erlbaum, 579-84.

- (forthcoming, ed.), Perceiving the World. New York: Oxford University Press.

O'Shaughnessy, B. (1973), 'Trying (as he Mental Pineal Gland)', Journal of Philosophy, 70: 365-86.

(C) 2010 Blackwell Publishing Ltd. 
(1991), 'Searle's Theory of Action', in E. Lepore and R. Van Gulick (eds) John Searle and His Critics. Cambridge, MA: Blackwell, 271-87.

Pacherie, E. (2000), 'The Content of Intentions', Mind \& Language, 15: 400-32.

Paulignan, Y., Jeannerod, M., MacKenzie, C. and Marteniuk, R. (1991), 'Selective Perturbation of Visual Input during Prehension Movements. 2. The Effects of Changing Object Size', Experimental Brain Research, 87: 407-20.

Paulignan, Y., MacKenzie, C., Marteniuk, R. and Jeannerod, M. (1991), 'Selective Perturbation of Visual Input during Prehension Movements. I. The Effects of Changing Object Position', Experimental Brain Research, 83: 502-12.

Peacocke, C. (1999), Being Known. Oxford: Oxford University Press.

- (2001), 'Does Perception have a Nonconceptual Content?', Journal of Philosophy, 98: 239-64.

Pelisson, D., Prablanc, C., Goodale, M. A. and Jeannerod, M. (1986), 'Visual Control of Reaching Movements without Vision of the Limb. II. Evidence of Fast Unconscious Processes Correcting the Trajectory of the Hand to the Final Position of a Double-Step Stimulus', Experimental Brain Research, 62: 303-11.

Perry, J. (2001), Knowledge, Possibility and Consciousness. Cambridge, MA: MIT Press.

Riddoch, M. J., Edwards, M. G. and Humphreys, G. W. (1998), 'Visual Affordances Direct Action: Neuropsychological Evidence from Manual Interference', Cognitive Neuropsychology, 15: 645-93.

Rock, I. (1983), The Logic of Perception. Cambridge MA: MIT Press.

Rodriguez-Pereyra, G. (2002), Resemblance Nominalism. Oxford: Clarendon.

Sainsbury, R. M. (1997), 'Easy Possibilities', Philosophy and Phenomenal Research, 57: 907-19.

Schmidt, R. A. (1975), 'A Schema Theory of Discrete Motor Skill Learning', Psychological Review, 82: 225-60.

Searle, J. (1983), Intentionality. Cambridge: Cambridge University Press.

Siegel, S. (2006a), 'Which Properties are Represented in Perception?', in T. Gendler Szabo and J. Hawthorne (eds) Perceptual Experience. Oxford: Oxford University Press, 481-503. (2006b), 'Subject and Object in the Contents of Visual Experience', Philosophical Review, 115: 355-88.

Theodoratus, D. H. and Chiszar, D. (2000), 'Habitat Selection and Prey Odor in the Foraging Behavior of Western Rattlesnakes, Crotalus viridis', Behavior, 137: 119-35.

Travis, C. (2004), 'The Silence of the Senses', Mind, 113: 57-94.

Wilcox, S. and Jackson, R. (2002), 'Jumping Spider Tricksters: Deceit, Predation and Cognition', in M. Bekoff, C. Allen and G. Burghardt (eds) The Cognitive Animal: Empirical and Theoretical Perspectives. Cambridge, MA: MIT Press, 27-34.

\footnotetext{
(C) 2010 Blackwell Publishing Ltd.
} 


\section{Author Query Form}

\begin{tabular}{ll}
\hline Journal & EJOP \\
Article & 407
\end{tabular}

Dear Author,

During the copy-editing of your paper, the following queries arose. Please respond to these by marking up your proofs with the necessary changes/additions. Please write your answers clearly on the query sheet if there is insufficient space on the page proofs. If returning the proof by fax do not write too close to the paper's edge. Please remember that illegible mark-ups may delay publication.

\begin{tabular}{|c||c|c||c|}
\hline Query No. & \multicolumn{1}{|c|}{ Description } & Author Response \\
\hline QI & $\begin{array}{l}\text { Author: O'Shaughnessy (1973) is not cited in the text.Please confirm } \\
\text { where it has to be cited or deleted from the reference list. }\end{array}$ & \\
\hline & & & \\
\hline & & & \\
\hline
\end{tabular}

